\title{
Technology Transfer
}

National Cancer Institute

\section{Source}

National Cancer Institute. Technology Transfer. NCI Thesaurus. Code C15434.

The process of converting scientific findings from research laboratories into useful products by the commercial sector. 